\title{
Drift or Shift? Propositions for Changing Roles of Administrations in E-Government
}

\author{
Ralf Klischewski \\ German University in Cairo \\ 11835 New Cairo City, Egypt \\ ralf.klischewski@guc.edu.eg
}

\begin{abstract}
As transaction costs of web-based interaction in e-government continue to decrease, the actors involved are forced to reconsider their roles and value propositions. This paper builds on previous research on government transformation and introduces three propositions on how new opportunities opened up by emerging web technologies and methods lead to a paradigmatic change of the role of administrations in e-government. The propositions are developed in the areas of information management, creation of service value, and leadership in administration, based on identifying technology-induced challenges ("anomalies") as well as new opportunities leading to new role conceptions in administrations.
\end{abstract}

Keywords: government transformation, administrative roles, paradigm shift, web technologies.

\section{Introduction}

New internet technologies, new methods of designing web applications and new opportunities for online interaction have an impact also on e-government. Previous research has discussed for example the new opportunities induced by web 2.0, and citizens, companies and even government employees are increasingly seizing these opportunities as part of their e-government activities. As starting point of this paper we assume that (1) these emerging technologies, methods and communication channels lead to, economically speaking, a decrease of transaction costs of e-government related interaction, e.g. through less effort for web-based information sharing, service orchestration etc., and (2) therefore all actors involved will (have to) reconsider their roles and value propositions in the e-government networking sphere.

Following these assumptions, we must be able to detect the change of the role of administrations as leading actors in e-government, especially the significant changes. To this end this paper introduces propositions on how new opportunities opened up by emerging web technologies and methods induce a paradigmatic change of the role of administrations in e-government. The contribution to the field of e-government is that these propositions can be further developed for e.g. hypotheses testing in order to collect empirical evidence to what extent administrations do change their behavior and role conception. The practical relevance lies in raising the awareness for 
stakeholders involved in e-government to reflect about the change of environment, to detect drifts in role implementation and/or to strategically plan for a shift in role definition.

The approach of this research is explorative and conceptual: It develops the propositions for role change based on analyzing the potential for a paradigmatic change. The conception of paradigmatic follows the well-known work of Thomas Kuhn who considered a "paradigm" (or "disciplinary matrix") what members of a scientific community share as a constellation of beliefs, values, and techniques, thus constituting an entire 'worldview' of this community. When phenomena are encountered which cannot be explained by the prevailing (i.e. accepted) paradigm they are considered "anomalies" or non-relevant outliers. However, too many significant anomalies against a current paradigm amount to a significant challenge and can throw the community into crisis, leading to new ideas and eventually a new paradigm.

Based on this understanding the research question is: How do new opportunities opened up by emerging web technologies challenge existing paradigms of administrations' role in e-government and what could be new role paradigms accordingly? After reviewing the literature on government transformation in relation to change of roles and paradigms in e-government (section 2), emerging web technologies are defined and discussed in terms of how governments and government consultants perceive their relevance (section 3). The development of the propositions (section 4) is based on selecting and defining three prevailing role definitions in administrations, identifying current technology-induced challenges ("anomalies") of these role paradigms potentials as well as new opportunities beyond these paradigms, and pointing out possibly new role conceptions in administrations. The conclusion summarizes the propositions for change of the role of administrations in e-government and points to future research.

\section{Transformation in (E-)Government?}

Change of organization in relation to deployment and use of information systems is an extensively discussed topic in the literature, for example using IS as an opportunity for business process reengineering, but there is no simple and direct alignment between the two concepts. This discussion has reached also the domain of egovernment: most authors agree that the use of new information and communication technologies do have an impact on the way e-government is implemented. But there is no causal relationship which can sufficiently explain the phenomena in practice, and there seems to be even little evidence that transformation is taking place [30].

Informatics and computer science tend to perceive organizational change as a sequence of transitions from one state to the next, much alike to the widespread 'unfreeze-change-refreeze' model in change management. However, research in political science has explored the topic of institutional change from many more perspectives. While tracing these perspectives is beyond the scope of this paper, we will follow here the viewpoint of J. Olsen [22] who states that "institutions have a role in generating both order and change and in balancing the two" and "understanding order and change are two sides of the same coin and there is a need to know what processes and conditions may maintain or challenge the status quo" (p. 4f). In view of 
the debate on institutionalization, Olsen [ibid.] considers the organizational identity to be based on: (a) clarity and agreement about behavioral rules (including allocation of formal authority), (b) consensus concerning how behavioral rules are to be described and justified (with a common vocabulary, expectations and success criteria), and (c) shared conceptions of what are legitimate resources (and who should control them). Such kind of institutional identity frames also the definition and interpretations of roles (on individual and institutional level) which can be considered as part of the shared mindset of government employees.

The literature reflecting on changing paradigms and roles of administrations in relation to e-government is still scarce, but the topic seems to be emerging. Scholl [25] has reviewed the organizational literature and makes use of the distinction firstorder changes (incremental, planned, and reaching for minor improvements) and second-order changes (extending to a radical organizational change involving a paradigmatic shift). He concludes that "organizational transformation is of comparatively slow pace and is mostly first-order change oriented. Organizational 'drift,' 'spread,' 'slippage,' and 'creep' [...], that is, evolutionary transformation, are much more likely drivers and embodiments of change in the public sector than second-order or revolutionary transformations." (p. 3) Scholl argues further that for identifying second-order changes the research should be interdisciplinary and also take into account not only G2C but also study phenomena in G2B, G2G and internal affairs.

After reviewing the literature on transformational government, van Veenstra and Zuurmond [29] conclude that transformation points to both process and product, "referring to a paradigm shift of fundamental assumptions and to a gradual change in behavior of individuals within an organization" (p. 235). That means, observation of gradual changes might come along with a 'paradigm shift', i.e. a radical change in the common beliefs of the actors involved. This can be in line with the findings of Scholl [25] proposing that second-order transformations can be observed rather in later stages of e-government development, preceded by a series of first-order changes.

With claiming the difference between e-governance and e-government (e.g. [12, 18]), a new level of abstraction has been opened up, pointing to the need for redefining governance objectives, methods and structures vis-à-vis the changing mode of technically mediated service delivery. More explicitly, Taylor and Lips [27] question the "e-government paradigm" (in particular the mostly shared assumption that e-government per se is 'citizen-centric') and recommend widening the scope of discussing the citizen-government relationship so that the field will become more theoretically informed.

Foreseeing the transformation of public service delivery, research has set out to investigate the transformation of the fundamental relationship between government, community and citizens [14]. Assuming that digital technologies affect functions of direction, control and organization of governments and their dominions, governments have to reconsider their roles to maintain their power in the 'digital state' [33]. In view of the new technical opportunities administrations indeed seem to have choices, for example designing service delivery like an e-government shop or developing an electronic community [26]. Therefore recommendations have been made to consider the (new) role of the government throughout the whole process of e-government development and design $[20,32]$. 
As digitization and virtualization are more and more affecting the government domain, research aims to look ahead to determine the government's role and responsibilities in the future. In the eGovRTD2020 project $[4,31]$ this had been one of the thirteen research themes, asking e.g. for what kind of virtual citizenship will appear, or whether different legislation is needed for the increasingly non-physical and borderless world and who would define implement the laws. In order to avoid organizational 'drift' or 'creep', some governments try to proactively set the path for a shift. For example the UK Cabinet Office [5] has coined the term 'transformational government' to prescribe the way for achieving more citizen- and business-centric public service delivery, trying to strengthen the link between e-government strategy and implementation. In the same line, van Veenstra et al. [28] identify the "absence of a transformational mindset" as one of the main barriers for transformation (along with a lack of knowledge about necessary changes and a lack of change in the organization structure).

In summary, throughout the last decade some research on transformation in egovernment has emerged, but empirical evidence or even propositions remain scarce. From the methodological perspective it seems that transformations can be detected primarily in the change of institutional agreements and in the mindset of the actors involved, usually as a consequence of an accumulation of marginal or gradual changes. This supports the approach chosen here to seek for accumulating challenges ("anomalies") of existing role paradigms in administrations in order to reach for propositions of role changes.

\section{Emerging Web Technologies: Challenges and Opportunities}

During the last decade several new web technologies and methods have emerged, leading to new opportunities for designing and operating e-government applications. For the remainder of the paper we mean by the term 'emerging web technologies' technologies and methods providing the following internet-based functionalities:

- Visualization: Increasing use and integration of maps, pictures, videos for enhanced and/or new services.

- Interactivity: Enhanced two-way communication, forums, easy-to-do resource sharing, etc.

- Semantic structuring: Use of tagging and ontologies for mark-up and automatic processing of informational and functional resources.

- Channel and content federation: Integration of mobile devices, multimedia, mashups, crowdsourcing, etc.

- Smart agency: Mission-based finding and combining content and services on behalf of users.

Most of the above functionalities are also embraced by the term 'web 2.0' which was originally coined by O'Reilly denoting principles such as the Web as platform, harnessing collective intelligence, data as the next 'Intel inside,' end of the software release cycle, lightweight programming models, software above the level of single device, and rich user experiences [2]. It is important to note that the novel aspects are not the technical specifications as such, but rather the way application developers and 
end-users make use of these technologies and thereby create new design patterns (i.e. methods) and business models. Often the term 'social computing' is used synonymously, denoting "a set of open, web-based and user-friendly applications that enable users to network, share data, and co-produce content" ([1], p. 15).

Not surprisingly consultants have been the first to point out how to make use of these emerging web technologies in administrations. Gartner [7, 8] has predicted reusability of content and services and a shift of emphasis away from single, one-stop shop portals to more networked solutions; they even expect the establishment of virtual government strategies defining how to participate in a variety of virtual communities, embracing government employees as well as citizens. And the "innovation expert" Anthony Williams (co-author of the best-seller 'Wikinomics') is quoted that "the Web offers the public sector tremendous opportunities to transform service delivery, make smarter policies, flatten silos and reinvigorate government" ([16], p. 30) and that due to institutional rigidity significant changes will take time, but there is an opportunity to change the division of labor for the public good.

Implications of these new technologies and opportunities from the perspective of administrations are now also on the governmental agenda. A research report by the European Commission [22] identifies a set of domains of government activity for which web 2.0 solutions are expected to be relevant: regulation, cross-agency collaboration, and knowledge management as back office domains; and political participation and transparency, service provision, and law enforcement as front office domains (p. 23). The report identifies various user roles (designing and delivering the service, providing comments and reviews, providing automatic attention and 'taste data' by using the service) and points out that such proactive user roles imply that "governments have no power to decide whether or not web 2.0 applications should be adopted and implemented, either by civil servants or citizens" (p. 41). Opportunities provided by web 2.0 applications are considered to relate to strategic objectives such as making government more simple and user-oriented, transparent and accountable, participative and inclusive, as well as joined-up and networked. On the contrary there are many challenges identified because of common risks of web 2.0 with particular relevance in the government context due to its institutional role and universal service obligations: low participation, participation restricted to an elite, low quality of contribution, loss of control due to excessive transparency, destructive behavior by users, manipulation of content by interested parties, and privacy issues.

It seems that the advent of the emerging web technologies creates an unexpected dilemma for governments. On one hand, governments seek to use the new opportunities in line with their strategic objectives; for example the 2009 "Ministerial Declaration on eGovernment" [19], unanimously approved by the European ministers of interior, states as the first shared objective for the period until 2015: "Citizens and businesses are empowered by eGovernment services designed around users needs and developed in collaboration with third parties, as well as by increased access to public information, strengthened transparency and effective means for involvement of stakeholders in the policy process;" and the foreword of EU workshop report on 'Public Services 2.0' points out: "Governments around Europe are aware of these new possibilities and actively started exploring them." ([24], p. 7). 
On the other hand, however, analysts have posted numerous blogs indicating that governments have significant problems embracing these emerging web technologies: blurring boundaries and growing tension between hierarchy and collaborative networks are threatening established social barriers (e.g. [13]) and, for various reasons, administrations seem to be unwilling to challenge the status quo (e.g. [9, 10]).

In summary, emerging web technologies have reached e-government, but the selfconception of administrative roles for embracing these technologies and seizing the opportunities seems not yet sufficient: it lacks the 'transformational mindset.' In order to assist administrative change management and support research in following up, the following section elaborates three propositions for administrative role changes.

\section{Propositions for Role Change in Administrations}

Administrations are the implementers of e-government: they operate the e-government applications and - framed by existing laws and regulations - interact with the constituents and other actors via these platforms according to their interpretation of the governmental mission. In this context we mean by 'role' the actions and activities assigned to or required or expected of a person or group. We consider a role in administration to be 'paradigmatic' when the community of government employees shares the same belief regarding what kind of work they are obliged to perform or not. Given the myriad of specific administrative functions, such paradigmatic roles can only be conceptualized on a rather abstract level, making reference to what government and/or administration as a whole are supposed to do or not (which then prescribes the individual work behavior). Such kind of role interpretations are not necessarily fixed in writing, but can be more importantly considered as part of the institutional identity and as the shared mindset of government employees of all ranks (see above, section 2).

This research is not empirical, i.e. does not validate to what extent any of the role definitions below actually are or will be prevailing in any administration. The purpose is to develop propositions by which future empirical research is expected to advance our knowledge about the impact of emerging web technologies on e-government and/or to assist change management in administrations regarding the strategic use of these technologies.

Based on the web 2.0 user roles and related governance issues pointed out in the previous section, the areas selected for proposition development are information management, creation of service value, and leadership in administration. The proposition development follows the sequence of defining prevailing role in administrations for the selected area, identifying current technology-induced challenges ("anomalies") of these role paradigms, identifying new opportunities beyond these paradigms, and pointing out possibly new role conceptions in administrations.

\subsection{From Information Monopolist to Information Provider, Broker, and Consumer}

Role definition. The history of administration is also a history of bureaucracy, the heritage of which includes well-established hierarchies, formal division of powers, 
and a strong sense of leadership. As the executive branch of government, administrations are rule-followers who develop and enact standardized procedures that guide the treatment of (almost) all cases. More often than not this mindset extends to any cooperation with external partners or dealing with its own employees: administrations are the leaders who maintain the core values of bureaucracy for the public good.

Challenges. E-government applications enable the extension of administrative processes into the sphere of citizens and businesses and cut across various agencies. In result we find numerous information providers and managers participating in administrative processes, and information ownership and processing control is increasingly distributed. Furthermore the new emerging technologies allow tapping on completely new sources of information: for example the website mybikelane.com was launched by a New York citizen asking fellow cyclists to post photos of cars illegally parked on bike lanes - with the result that now information on countless regulatory offenses is available, structured and managed without any control by administration (for more similar cases see e.g. [23]).

Opportunities. As governments seek to be more transparent and accountable, websites such as theyworkforyou.com (for keeping tabs on UK parliament activities) or data.gov (for public access to high value, machine readable datasets generated by the US federal administration) open up new venues for sharing relevant information on a large scale. And there are many cases in which participatory large-scale collection of information is for the benefit of administrative performance, for example urban planning or monitoring environmental risks and neighborhood safety, many of these supported by new technologies structuring the information processing by means of maps or other visual concepts [3].

Role change. Since the role of administrations as information monopolists cannot sustain, seizing the new opportunities and alignment with the strategic objectives could be framed by a new role of administrations as information provider, broker, and consumer. This would acknowledge that e-government by default incorporates shared information processing, and it allows setting new specific policies such as focusing on stewardship and usefulness [6] which includes handling information with care and integrity, regardless of its original purpose or source, and promoting access to and use of government information by a wide variety of public and private users.

\subsection{From Sole Care Taker to Service Provider and Network Manager}

Role definition. When it comes to the question who takes care of the citizens' concerns vis-à-vis the state, for long time the answer could not embrace any significant contributor but the public administration itself. Emerging form the tradition of the kingdoms, citizens were considered entrusted subjects and the administrations are the sole care takers to deal with them.

Challenges. In 2003 the UK Office of the e-Envoy [21] published a policy framework draft aiming at the establishment of 'e-intermediaries' supplementing direct government channels to citizens with additional value-added services built around citizens' needs. While in some areas intermediaries are well established for a long time (e.g. tax accountants), the emerging web technologies enable many new actors 
('competitors') to offer admin-related services. The most well-known examples are web portals providing information on and access to public service, operated by companies, public-private partnerships or even by the citizens themselves (see e.g. bccdiy.com, the "community-powered Birmingham City Council site"). Furthermore, the provision of machine-readable service descriptions and interfaces changes the distribution of cost and benefit among service providers, brokers and consumers [17].

Opportunities. As transaction costs are decreasing, governments may indeed reconsider: "What is the best way to divide labor for the public good?" [16]. A wellknown example is "Peer-to-Patent" (peertopatent.com), an initiative endorsed by the US Patent Office aiming to improve the process for reviewing patents by allowing voluntary contributions to assess and rate the proposals, thus involving external experts in assessing the current state of the art on the issue addressed by the patent. There are many cases where administrations can benefit from outsourcing and crowdsourcing and/or tapping on new potentials (for more examples and analysis see [23]). And the advent of new electronic intermediaries could support the citizens' development into active consumers of public services [15].

Role change. Restraining the administration's role as the sole care takers of citizens' concerns would deprive administrations and constituents of potential increase in government effectiveness and service quality. Redefining the role as service provider and service network manager allows administrations to focus on their core value proposition as well as to create and manage e-service networks.

\subsection{From Bureaucratic Leader to Facilitator and Framework Provider}

Role definition. The history of administration is also a history of bureaucracy, the heritage of which includes well-established hierarchies, formal division of powers, and a strong sense of leadership. As the executive branch of government, administrations are rule-followers who develop and enact standardized procedures that guide the treatment of (almost) all cases. More often than not this mindset extends to any cooperation with external partners or dealing with its own employees: administrations are the leaders who maintain the core values of bureaucracy for the public good.

Challenges. As quoted above, "governments have no power to decide whether or not web 2.0 applications should be adopted and implemented, either by civil servants or citizens." Among other, it leads to blurring boundaries between internal and external collaboration, to new methods of processing relevant information and providing services (see above sections). Bureaucracy is mainly challenged by realizing that anticipation of procedures is decaying.

Opportunities. Many issues in e-government need leadership intervention in order to balance values which are on one hand conflicting but on the other hand of equal importance in the public interest, for example the mediating the tension between information privacy and information access [11]. And with respect to emerging web technologies, a social media policy is needed that guides especially admin employee behaviors.

Role change. Identifying leadership with bureaucracy is not compatible with making use of emergent web technologies. Analysts recommend a bottom-up approach, where 
government agencies should let go control to facilitate engagement empowering employees: "This is the key ingredient, the secret sauce for government 2.0 initiatives to succeed [...] 'Let go' means that you cannot plan in advance, you cannot set a future state architecture, you cannot control your employees too tightly, you cannot make assumptions about where and how and when value will be generated." [10] However, this does not mean to subscribe (or surrender) to anarchy. Instead, administrations should resume leadership-related roles where it is more needed and more effective, mainly as facilitators and framework providers.

\section{Conclusion}

Assuming that emerging web technologies decrease transaction costs of e-government related interaction and therefore all actors involved will (have to) reconsider their roles and value propositions, this research has set out develop propositions that can be further used for collecting empirical evidence on the extent administrations do change their behavior and role conception. These propositions have been developed in the areas of information management, creation of service value, and leadership in administration, based on identifying technology-induced challenges ("anomalies") as well as new opportunities leading to new role conceptions in administrations (see below figure for summary).

\begin{tabular}{|l|l|l|l||}
\hline From Gov's as & info monopolist & sole care taker & bureaucratic leader \\
\hline $\begin{array}{l}\text { Challenges } \\
\text { "'anomalies") } \\
\text { based on web } \\
\text { technologies \& } \\
\text { methods }\end{array}$ & $\begin{array}{l}\text { relevant information } \\
\text { provided / managed } \\
\text { / owned by many, } \\
\text { often out of admin } \\
\text { control }\end{array}$ & $\begin{array}{l}\text { "competitors" offer } \\
\text { (value-added) } \\
\text { admin services }\end{array}$ & $\begin{array}{l}\text { empowerment of } \\
\text { citizens and admin } \\
\text { employees }\end{array}$ \\
\hline $\begin{array}{l}\text { Opportunities } \\
\text { based on web } \\
\text { technologies \& } \\
\text { methods }\end{array}$ & $\begin{array}{l}\text { information } \\
\text { dissemination to and } \\
\text { consumption from }\end{array}$ & $\begin{array}{l}\text { specific value } \\
\text { creation in a net- } \\
\text { work of electronic } \\
\text { service providers }\end{array}$ & $\begin{array}{l}\text { setting standards for } \\
\text { technical, semantic, } \\
\text { organizational, legal, } \\
\text { social "interoperability" }\end{array}$ \\
\hline To Gov's as & $\begin{array}{l}\text { information } \\
\text { provider, broker, } \\
\text { and consumer }\end{array}$ & $\begin{array}{l}\text { service provider } \\
\text { and network } \\
\text { manager }\end{array}$ & $\begin{array}{l}\text { facilitator and } \\
\text { framework provider }\end{array}$ \\
\hline
\end{tabular}

Fig. 1. Drift or shift? Propositions for changing roles of administrations in e-government

The practical relevance of these propositions lies in raising the awareness of stakeholders involved in e-government. Given the change of environment due to increasing use of emerging web technologies, governments and administrations should reconsider their basic assumptions, i.e. paradigms. The assumptions discussed in this paper are primarily concerned with administrative roles, but the analysis and reconsideration 
on the institutional level should extend also to the role-related behavioral rules and authorities, to their description and justification, and to the (shared) control of resources. All of these issues are highly relevant for the design and implementation of e-government applications and infrastructures; hence they should be on the agenda of future e-government research, from the technical as well as from the organizational perspective. Will forthcoming studies reveal a strategically aligned shift or rather an unintended drift in administrative role implementation? The answer, of course, depends much on the stakeholders' readiness and willingness to reflect on the challenges and opportunities induced by emerging web technologies, and to what extent this will lead to a proactive approach in re-balancing stability and change of governmental institutions.

Acknowledgments. The above propositions have originally been presented at the Preconference for the EU 5th Ministerial e-Government Conference "e-Government Research and Innovation: Empowering Citizens through Government Services across Sectors and Borders," Malmö, November 18, 2009.

\section{References}

1. Ala-Mutka, K., et al.: The Impact of Social Computing on the EU Information Society and Economy. European Commission, Joint Research Centre, Institute for Prospective Technological Studies (2009)

2. Anderson, P.: What is Web 2.0? Ideas, technologies and implications for education. JISC Technology and Standards Watch (2007)

3. Bekkers, V., Moody, R.: Visual Culture and Electronic Government: Exploring a New Generation of E-Government. In: Wimmer, M.A., et al. (eds.) EGOV 2009, pp. 257-269. Springer, Berlin (2009)

4. Bicking, M.: Roadmapping future e-Government research: Government's role and responsibilities in the virtual world. In: Seventh IFIP International Conference on eBusiness, e-Services, and e-Society, pp. 469-480. Springer, Heidelberg (2007)

5. Cabinet Office: Transformational Government: Enabled by Technology. e-Government Unit of the Cabinet Office (2005),

http: / /www. cabinetoffice.gov.uk/media/141734/

transgov-strategy.pdf

6. Dawes, S.S.: Information policy meta-principles: stewardship and usefulness. In: Proceedings of the 43rd Annual Hawaii International Conference on System Sciences (HICSS '10), IEEE Computer Society Conference Publishing Services (2010)

7. DiMaio, A.: Government and Web 2.0: The Emerging Midoffice. Gartner Report (2007)

8. DiMaio, A.: The E-Government Hype Cycle Meets Web 2.0. Gartner Report (2007)

9. DiMaio, A.: Why North Americans Will Get Government 2.0 and Europeans Won't, http: //blogs.gartner.com/andrea_dimaio/ (October 30, 2009)

10. DiMaio, A.: The Government 2.0 Critical Success Factor Is To Let It Go, http: //blogs.gartner.com/andrea_dimaio/ (November 1, 2009)

11. Duncan, G.T., Roehrig, S.F.: Mediating the Tension between Information Privacy and Information Access: The Role of Digital Government. In: Garson, G.D. (ed.) Public Information Technology: Policy and Management Issues, pp. 94-119. Idea Group Publishing, Hershey (2003) 
12. Finger, M., Pécoud, G.: From e-Government to e-Governance? Towards a model of eGovernance. Electronic Journal of e-Government 1(1), 1-10 (2003)

13. Hinchcliffe, D.: Government 2.0: A tale of "risk, control, and trust" (2009), http: / /blogs. zdnet. com/Hinchcliffe/ ?p=811 (Posted September 9, 2009)

14. Jones, S., Hackney, R., Irani, Z.: Towards e-government transformation: conceptualising "citizen engagement": A research note. Transforming Government: People, Process and Policy 1(2), 145-152 (2007)

15. Josefsson, U., Ranerup, A.: Consumerism revisited: The emergent roles of new electronic intermediaries between citizens and the public sector. Information Polity: The International Journal of Government \& Democracy in the Information Age 8(3/4), 167-180 (2003)

16. Klein, P.: Web 2.0: Reinventing Democracy. CIO Insight/Expert Voices, 30-34 (2008), http: / / anthonydwilliams.com/ wp-content/uploads/web2_reinventingdemocracy.pdf

17. Klischewski, R., Ukena, S.: A Value Network Analysis of Automated Access to eGovernment Services. In: Hansen, H.R., Karagiannis, D., Fill, H.-G. (eds.) 9th International Conference on Business Informatics (Part 2), Österreichische Computer Gesellschaft, Wien, pp. 585-594 (2009)

18. Kolsaker, A., Lee-Kelley, L.: 'Mind the Gap II': E-Government and E-Governance. In: Wimmer, M.A., Scholl, J., Grönlund, Å. (eds.) EGOV 2007. LNCS, vol. 4656, pp. 35-43. Springer, Heidelberg (2007)

19. Ministerial Declaration on eGovernment, Malmö, Sweden (2009), http: / / www.epractice.eu/files/ Malmo\%20Ministerial\%20Declaration\%202009.pdf (November 18, 2009)

20. Mofleh, S., Wanous, M., Strachan, P.: Understanding national e-government: the role of central government. Electronic Government, an International Journal 6(1), 1-18 (2009)

21. Office of the e-Envoy: Policy Framework for a mixed economy in the supply of egovernment services, UK Cabinet Office,

http: //archive.cabinetoffice.gov.uk/e-envoy/

22. Olsen, J.: Change and continuity. An institutional approach to institutions of democratic government. European Political Science Review 1(1), 3-32 (2009)

23. Ossimo, D.: Web 2.0 in Government: Why and How? European Commission, Joint Research Centre, Institute for Prospective Technological Studies (2008)

24. Ossimo, D., et al.: Public Services 2.0 - Web 2.0 from the periphery to the centre of public service delivery. In: Report from the ePractice Workshop, European Commission, Brussels (2009)

25. Scholl, H.J.: Organizational Transformation Through E-Government: Myth or Reality? In: Wimmer, M.A., Traunmüller, R., Grönlund, Å., Andersen, K.V. (eds.) EGOV 2005. LNCS, vol. 3591, pp. 1-11. Springer, Heidelberg (2005)

26. Steyaert, J.: Local governments online and the role of the resident - Government shop versus electronic community. Social Science Computer Review 18(1), 3-16 (2000)

27. Taylor, J.A., Lips, A.M.B.: The citizen in the information polity: Exposing the limits of the e-government paradigm. Information Polity 13(3-4), 139-152 (2008)

28. Veenstra, A.F.v., Klievink, B., Janssen, M.: Barriers for transformation: Impediments for transforming the public sector through e-government. In: 17th European Conference on Information Systems, Verona, Italy (2009), http: / / www.ecis2009.it/papers/ecis2009-0399.pdf

29. Veenstra, A.F.v., Zuurmond, A.: Opening the Black Box: Exploring the Effect of Transformation on Online Service Delivery in Local Governments. In: Wimmer, M.A., et al. (eds.) EGOV 2009, vol. 5693, pp. 234-244. Springer, Berlin (2009) 
30. West, D.M.: E-Government and the Transformation of Service Delivery and Citizen Attitudes. Public Administration Review 64(1), 15-27 (2004)

31. Wimmer, M.A., Codagnone, C., Janssen, M.: Future e-government research: 13 research themes identified in the eGovRTD2020 project. In: Proceedings of the 41st Hawaii International Conference on System Sciences (HICSS '08). IEEE Computer Society Conference Publishing (2008)

32. Zappen, J.P., Harrison, T.M., Watson, D.: A New Paradigm for Designing E-Government: Web 2.0 and Experience Designs. In: Chun, S.A., Janssen, M., Gil-Garcia, J.R. (eds.) dg.o 2008: Proceedings of the 9th Annual International Digital Government Research Conference, pp. 17-26 (2008)

33. Zuccarini, M.: Transformation of Government Roles toward a Digital State. In: Anttiroiko, A.-V., Mälkiä, M. (eds.) Encyclopedia of digital government, pp. 1562-1565. Idea Group Reference, Hershey (2007) 